\title{
2012s-27 \\ Technology Transfers and Industry Closures
}

\author{
Daniel Leonard, Ngo Van Long
}

\begin{tabular}{c}
\hline Série Scientifique \\
Scientific Series
\end{tabular}

\author{
Montréal \\ Octobre 2012
}

(C) 2012 Daniel Leonard, Ngo Van Long. Tous droits réservés. All rights reserved. Reproduction partielle permise avec citation du document source, incluant la notice ().

Short sections may be quoted without explicit permission, if full credit, including $\odot$ notice, is given to the source.
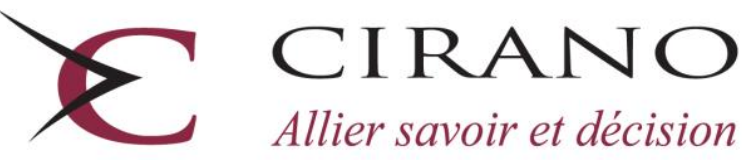

Allier savoir et décision

Centre interuniversitaire de recherche en analyse des organisations 


\section{CIRANO}

Le CIRANO est un organisme sans but lucratif constitué en vertu de la Loi des compagnies du Québec. Le financement de son infrastructure et de ses activités de recherche provient des cotisations de ses organisations-membres, d'une subvention d'infrastructure du Ministère du Développement économique et régional et de la Recherche, de même que des subventions et mandats obtenus par ses équipes de recherche.

CIRANO is a private non-profit organization incorporated under the Québec Companies Act. Its infrastructure and research activities are funded through fees paid by member organizations, an infrastructure grant from the Ministère du Développement économique et régional et de la Recherche, and grants and research mandates obtained by its research teams.

\section{Les partenaires du CIRANO}

\section{Partenaire majeur}

Ministère du Développement économique, de l'Innovation et de l'Exportation

\section{Partenaires corporatifs}

Autorité des marchés financiers

Banque de développement du Canada

Banque du Canada

Banque Laurentienne du Canada

Banque Nationale du Canada

Banque Royale du Canada

Banque Scotia

Bell Canada

BMO Groupe financier

Caisse de dépôt et placement du Québec

Fédération des caisses Desjardins du Québec

Financière Sun Life, Québec

Gaz Métro

Hydro-Québec

Industrie Canada

Investissements PSP

Ministère des Finances du Québec

Power Corporation du Canada

Rio Tinto Alcan

State Street Global Advisors

Transat A.T.

Ville de Montréal

\section{Partenaires universitaires}

École Polytechnique de Montréal

HEC Montréal

McGill University

Université Concordia

Université de Montréal

Université de Sherbrooke

Université du Québec

Université du Québec à Montréal

Université Laval

Le CIRANO collabore avec de nombreux centres et chaires de recherche universitaires dont on peut consulter la liste sur son site web.

Les cahiers de la série scientifique (CS) visent à rendre accessibles des résultats de recherche effectuée au CIRANO afin de susciter échanges et commentaires. Ces cahiers sont écrits dans le style des publications scientifiques. Les idées et les opinions émises sont sous l'unique responsabilité des auteurs et ne représentent pas nécessairement les positions du CIRANO ou de ses partenaires.

This paper presents research carried out at CIRANO and aims at encouraging discussion and comment. The observations and viewpoints expressed are the sole responsibility of the authors. They do not necessarily represent positions of CIRANO or its partners. 


\title{
Technology Transfers and Industry Closures
}

\author{
Daniel Leonard ${ }^{*}$, Ngo Van Long ${ }^{\dagger}$
}

\begin{abstract}
Résumé / Abstract
Certaines industries ont disparu des pays de l'OCDE et ont émigré dans les pays émergents. Dans un monde globalisé, les avances technologiques sont bénéfiques mais les pays avancés souffrent du chômage qui en est la conséquence parce que certains employés n'ont pas les qualifications requises pour d'autres empois. Nous analysons les conséquences de ces transferts de technologie qui peuvent être la cause de la disparition de certaines industries. Quand cela arrive, le pays souffre d'une diminution sévère de bien-être, qui peut être renversée avec d'avantage de transferts. Si un pays veut soutenir son industrie, la meilleure taille est la plus petite. Au final, la conclusion est claire : les transferts de technologie militent contre un support de l'industrie.
\end{abstract}

Mots clés : transferts de technologie, fermetures d'industries.

There has been a shift of manufacturing industries from OECD countries to emerging countries. In a competitive global economy increases in productivity in any country are generally welfare-enhancing. The established industrialised countries can suffer from the collapse of some industries, and from the associated increase in unemployment. We model this process and analyze the interactions between various rigidities that cause it, such as the minimum viable scale of an industry or the number of workers who lack the necessary skills to change jobs. When, under free trade, the technology transfer causes the manufacturing industry to collapse in the home country, it experiences a discrete drop in welfare and the price of the manufactured good rises sharply. Further transfers may reverse these results. The optimal level of protection is the minimum size required to operate. Conditions that make supporting an ailing industry worthwhile can be interpreted in several ways but the conclusion is inescapable: technology transfers adversely affect arguments for industry protection at home.

Keywords: Technology Transfers, Industry Closures.

\footnotetext{
${ }^{*}$ Flinders University,GPO box 2100, Adelaide, 5001, Australia. Email: daniel.leonard@ @ flinders.edu.au.

${ }^{\dagger}$ Department of Economics, McGill University, Montreal H3A 2T7, Canada.
} 


\section{Introduction}

During the last few decades there has been a shift of manufacturing industries from OECD countries to emerging countries. Manufactured products from the latter have progressively become of better quality and replaced the more expensive home grown products in North America and Western Europe. This is not a new phenomenon. Post-war Japan used to produce cheap, shoddy goods but in a quarter of a century rose to become the standard of technological excellence in such diverse industries as car and electronic appliance manufacturing. Arguably, the technological advance of the newly industrialised economies can be partly accounted for by technology transfer from the more established industrialised economies.

This transfer of technology which, as many international trade theorists argue, is good for the world, has nonetheless adverse consequences for segments of the population in established industrialised countries.

There is growing unrest in western Europe and North America about the loss of jobs in 'rust belt' industries. This was always more pronounced in Europe than in the more flexible American labor market.

In a competitive global economy increases in productivity in any country are generally welfare-enhancing for all when smooth substitution takes place between capital and labor. (Except for cases of "immiserizing growth", where the growing economies suffer from severe terms of trade deterioration due to very inelastic demand for their exports.)

The premise of this paper is simple: this is not what we observe. The established industrialised countries can suffer from the collapse of some industries, and from the associated increase in unemployment.

Technological transfers do occur and whole industries do disappear in some countries. We are attempting to model this process and analyze the interactions between the various rigidities that may cause it, such as the 
minimum viable scale of an industry or the number of workers who cannot operate in another industry because they lack the necessary skills.

The size of a manufacturing industry is essential for its viability; the industry collapses below a given size. Some of our conclusions are: technology transfers may cause the home country manufacturing industry to collapse. When, under free trade, the technology transfer causes the manufacturing industry to collapse in the home country, it experiences a discrete drop in welfare and the price of the manufactured good rises sharply. Further transfers of technology to the foreign country may reverse these results. The optimal level of protection is the minimum size required to operate. Conditions that makes supporting an ailing industry worthwhile can be interpreted in several ways but the conclusion is inescapable: technology transfers adversely affect arguments for industry protection at home.

\section{Literature Review}

Our paper does not model how technology transfer takes place.

An early paper that discussed the resource cost of transferring technology know-how was Teece (1977). Teece disagreed with the "common belief that technology is nothing but a set of blueprints that is usable at nominal cost to all". He argued instead that "the cost of transfer, which can be defined to include both transmission and absorption costs, may be considerable when the technology is complex and the recipient firm does not have the capabilities to absorb the technology". His empirical research focused on measuring the costs of transmitting and absorbing all of the "relevant unembodied knowledge". These costs fall into four groups. First, there are pre-engineering technological exchanges, where the basic characteristics of the technology are described to the local firm. Second, there are costs of transferring and absorption of the process or product design, which require "considerable 
consulting and advisory resources". Third, there are "R\&D costs associated with solving unexpected problems and adapting or modifying technology". Fourth, there are training costs, which involve extra supervisory personnel. Teece found that empirically the resources required for international technology transfer are considerable and concluded that "it is quite inappropriate to regard existing technology as something that can be made available at zero social cost" (p. 259). Niosi et al. (1995) found that technology transfer costs are significant and mostly concentrated in training.

There are papers that abstract from the real cost of transfer. For example, in Kabiraj and Marjit (2003) and Mukherjee and Pennings (2006), technology transfer is via licensing, which does not use up real resources.

We have also neglected the role of intellectual property rights. Many authors point out that the degree of intellectual property protection influences the extent of technology transfer (for a survey of empirical evidence, see Mansfield, 1994).Ethier and Markusen (1996) presented a model involving a race among source-country firms to develop a new product that becomes outdated after two periods. The winning firm has the exclusive right to produce the good in the source country $(\mathrm{S})$, and can produce the good in the host country $(\mathrm{H})$ either by setting up a wholly owned subsidiary, or by licensing to a local firm. If the licensing contract is for one period, in the following period the former licensee, having learned the technology, can set up its own operation to compete against the source-country firm. Two-period licensing is ruled out because by assumption the local firm can breakaway in the second period without penalties. Their model captures essential elements of a situation where source-country firms "continually compete to introduce new products" and face possible dissipation of their knowledge-based capital. The authors assume that in the host country there is complete absence of protection of intellectual property. Their model highlights the interplay of locational and internalization considerations. It provides a key to understand 
why there are more direct investment between similar economies.

Markusen (2001) proposed a model of contract enforcement between a multinational firm and a local agent. He considered a two-period model where the agent learns the technology in the first period and can quit (with a penalty) and form a rival firm in the second period. The multinational can fire the agent after the first period and hire another agent in the second period. A main result is that if contract enforcement induces a shift from exporting to local production, both the multinational firm and the local agent are better off. Markusen's paper does not address the issue of the optimal speed of technology transfer.

Roy Chowdhury and Roy Chowdhury (2001) built a model of joint venture breakdown. They used a two-period setting, with a multinational firm and a local firm. They showed that for intermediate levels of demand, there is a joint venture formation between these firms in period 1 , followed by a joint venture breakdown in period 2 (when the two firms become Cournot rivals). In their model, the incentive for forming a joint venture is that both firms can learn from each other (the local firm acquires the technology while the multinational learns about the local labor market). The model does not allow the multinational to control the speed of technology transfer.

Among papers that deal with optimal timing decisions of multinational firms is Buckley and Casson (1981). They analyzed the decision of a foreign firm to switch from the "exporting mode" to the FDI mode (in setting up a wholly owned subsidiary). That paper did not deal with the problem of opportunistic behavior that would arise if there were a local partner. Horstmann and Markusen (1996) explored the multi-period agency contract between a multinational firm and a local agent (that sells the multinational's product) but in their model there was no technology transfer from the former to the latter. Their focus was to determine when a multinational would terminate its relationship with the local sales agent and establish its own 
sales operation. Rob and Vettas (2003) generated the time paths of exports and FDI, with emphasis on demand uncertainty and irreversibility. They did not consider the possibility of licensing or joint venture. Horstmann and Markusen (1987) explored a multinational firm's timing decision on investing (setting up a wholly owned subsidiary) in a host country in order to deter entry. Lin and Saggi (1999) explored a model of timing of entry by two multinationals into a host country market, under risk of imitation by local firms. There was no contractual issues in their model; the emphasis was instead on the leader-follower relationship. They showed that while an increase in imitation risk usually makes FDI less likely, there exist parameter values that produce the opposite result.

\section{The Model}

There are two countries, home and foreign, and two goods. One is the manufactured good, $m$; the other, the numeraire, is a sophisticated good, $s$, that only the home country knows how to produce. Individuals have the same preferences the world over. This is clearly a simplification but we are investigating technology transfers and drastic changes to the industrial structure, not how differences in tastes affect the pattern of trade.

Total labor available in each country is fixed and not moveable from one country to another. It is mobile between industries but a portion of workers in one industry are not employable in the other industry in the medium term so that an abrupt discrete downward shock can result in a finite level of unemployment.

In the medium term, which is the focus of our analysis, capital is industry specific. Car assembly lines cannot be quickly transformed into financial services offices, high-tech electronic machines or the gadgets required by software companies. Therefore we make the extreme assumption that capital is 
not moveable between industries.

The size of the industry also matters for its viability. Some (now very successful) software companies were started by two guys in a garage but car and airplane manufacturing as well as steel mills require a certain size to operate under the constant returns to scale technology and remain viable. Under our assumption that capital is industry specific the size of the industry is represented by its labor force. Therefore we postulate that there is a minimum level of labor input which is required for an industry to survive. It is linked to the existing level of capital in that industry but, because in this model, this is fixed in the medium term - the focus of our analysis we ignore this dependency and define the existing CRS technology as only available above a fixed level of labor force.

We assume that the technology of the manufacturing industry displays CRS provided that employment level in manufacturing, $L_{m}$, is at least equal to some critical level $\bar{L}_{m}$. To sharpen the analysis, we suppose that manufacturing output is identically zero if $L_{m}<\bar{L}_{m}$.

All agents have the same utility function. For agent $i$,

$$
u\left(c_{m i}, c_{s i}\right)=\left(c_{m i}\right)^{\beta}\left(c_{s i}\right)^{\sigma}, \beta>0, \sigma>0 \beta+\sigma=1
$$

where the subscripts $m$ and $s$ refer to the manufactured good and the sophisticated good, respectively.

Good $s$ being the numeraire good. The demand functions are

$$
p_{m} c_{m i}=\beta y_{i}, c_{s i}=\sigma y_{i}
$$

where $y_{i}$ is income of agent $i$ and $p_{m}$ is the price of the manufactured good.

Because of identical homothetic preferences, in each country per capital demand for each good depends only on per capita income and on the relative price $p_{m}$.

Variables for the foreign country are identified by an asterisk *. 
The home country has two industries, initially at least. The production functions are

$$
\begin{gathered}
Q_{m}=A_{m}\left(K_{m}\right)^{\gamma}\left(L_{m}\right)^{1-\gamma} \text { if } L_{m} \geq \bar{L}_{m} \\
Q_{s}=A_{s}\left(K_{s}\right)^{\delta}\left(L_{s}\right)^{1-\delta}
\end{gathered}
$$

The home country labor constraint is

$$
L_{m}+L_{s}=L \text { if } L_{m} \geq \bar{L}_{m}
$$

Recall that if $L_{m}$ is not high enough, the manufacturing industry collapses. Additionally, a portion $\bar{L}$ of the total labor force $L$ is not employable in the sophisticated industry as they lack the required skills. We assume $\bar{L}<\bar{L}_{m}$ so that the mobility of labor is unaffected while the manufacturing industry is viable.

\subsection{Initial Situation - with or without Free Trade}

We begin by charactersing the equilibrium where capital inputs are fixed but labor remains fully mobile between industries.

Equating the values of marginal product of labor in both industries, we have

$$
w=p_{m}(1-\gamma) A_{m}\left(\frac{K_{m}}{L_{m}}\right)^{\gamma}=(1-\delta) A_{s}\left(\frac{K_{s}}{L_{s}}\right)^{\delta}
$$

or

$$
A_{s}\left(\frac{K_{s}}{L_{s}}\right)^{\delta}=p_{m} \frac{1-\gamma}{(1-\delta)} A_{m}\left(\frac{K_{m}}{L_{m}}\right)^{\gamma}
$$

This gives the following monotone relationship between $p_{m}$ and $L_{m}$ :

$$
p_{m}=\left(\frac{1-\delta}{1-\gamma}\right)\left(\frac{A_{s}}{A_{m}}\right)\left(\frac{L_{m}}{K_{m}}\right)^{\gamma}\left(\frac{K_{s}}{L-L_{m}}\right)^{\delta}
$$


The larger $p_{m}$, the larger the size of the industry.

The home country GDP is $Y=y L$, where $y$ is per capita income.

We shall focus on employment in manufacturing, thus it is convenient to express GDP as a function of $L_{m}$ :

$$
Y=p_{m} Q_{m}+Q_{s}=p_{m} A_{m}\left(\frac{K_{m}}{L_{m}}\right)^{\gamma} L_{m}+A_{s}\left(\frac{K_{s}}{L-L_{m}}\right)^{\delta}\left(L-L_{m}\right)
$$

or, using (6)

$$
Y=p_{m} A_{m}\left(\frac{K_{m}}{L_{m}}\right)^{\gamma}\left[\left[L_{m} \frac{\gamma-\delta}{1-\delta}+L \frac{1-\gamma}{1-\delta}\right]\right]
$$

Therefore the home country individual demands are, from(2) and (9)

$$
\begin{gathered}
c_{m}=\beta A_{m}\left(\frac{K_{m}}{L_{m}}\right)^{\gamma}\left[L_{m} \frac{\gamma-\delta}{1-\delta}+L \frac{1-\gamma}{1-\delta}\right] \frac{1}{L} \\
c_{s}=\sigma p_{m} A_{m}\left(\frac{K_{m}}{L_{m}}\right)^{\gamma}\left[L_{m} \frac{\gamma-\delta}{1-\delta}+L \frac{1-\gamma}{1-\delta}\right] \frac{1}{L}
\end{gathered}
$$

We assume that the foreign country cannot produce good $s$, it only has the manufacturing industry. Let $p_{m}^{*}$ denote the relative price of good $m$ in the foreign country.

$$
\theta A_{m}^{*}\left(K^{*}\right)^{\gamma}\left(L^{*}\right)^{1-\gamma}=\theta Q_{m}^{*}
$$

where, initially, $\theta=1$. We assume $L^{*}>\bar{L}$.

Each individual in the foreign country receives his/her factor payments (capital and labor income, $y^{*}$ ) plus a transfer payment $t^{*}$ which is a share of the profit, $\left(p_{m}-p_{m}^{*}\right) X_{m}^{*}$, that exporters get from selling to the home country at a price $p_{m}$ which is higher than the production cost $p_{m}^{*}$, where $X_{m}^{*}$ is the total export of good $m$. As individuals are identical, this profit is redistributed uniformally. 


$$
y^{*}+t^{*}=\frac{p_{m}^{*} \theta Q_{m}^{*}+\left(p_{m}-p_{m}^{*}\right) X_{m}^{*}}{L^{*}}
$$

The foreign demand for good $m$ satisfies the condition

$$
p_{m}^{*} c_{m}^{*}=\beta\left[y^{*}+\left(p_{m}-p_{m}^{*}\right) \frac{X_{m}^{*}}{L^{*}}\right]
$$

Then

$$
c_{m}^{*}=\beta \theta A_{m}^{*}\left(\frac{K^{*}}{L^{*}}\right)^{\gamma}+\beta\left[\frac{p_{m}}{p_{m^{*}}}-1\right] \frac{X_{m}^{*}}{L^{*}}
$$

and

$$
c_{s}^{*}=\sigma\left[y^{*}+\left(p_{m}-p_{m}^{*}\right) \frac{X_{m}^{*}}{L^{*}}\right]
$$

The foreign country exports of good $m$ are

$$
X_{m}^{*}=\theta Q_{m}^{*}-L^{*} c_{m}^{*}=\sigma \theta A_{m}^{*}\left(K^{*}\right)^{\gamma}\left(L^{*}\right)^{1-\gamma}-\beta\left[\frac{p_{m}}{p_{m^{*}}}-1\right] X_{m}^{*}
$$

Let $\mu \equiv p_{m} / p_{m}^{*} \geq 1$. (Under free trade $\mu=1$.)

$$
X_{m}^{*}[1+(\mu-1) \beta]=\sigma \theta A_{m}^{*}\left(K^{*}\right)^{\gamma}\left(L^{*}\right)^{1-\gamma}
$$

Note that if $\mu=1$, the above equation indicates that $X_{m}^{*}$ depends only on $\theta A_{m}^{*}$ and $\left(K^{*}, L^{*}\right)$, all of which are characteristics of the foreign country. This is due to homothetic preferences.

For $\mu \neq 1$, we notice that a higher $\mu$ implies a lower $X_{m}^{*}$. So $\mu$, although endogenous to the model, can be interpreted as an index of the home country's restricive policies on its imports of good $m$ from the foreign country.

The home country's volume of imports of good $m$ is related to $L_{m}$ : it is monotone decreasing in $L_{m}$ :

$$
M_{m}=L c_{m}-Q_{m}=A_{m}\left(\frac{K_{m}}{L_{m}}\right)^{\gamma}\left[\beta \frac{1-\gamma}{1-\delta} L-\left(1-\beta \frac{\gamma-\delta}{1-\delta}\right) L_{m}\right]
$$


In equilibrium the home country imports good $m$, that is

$$
\begin{gathered}
L c_{m}>Q_{m} \text { or, } \beta A_{m}\left(\frac{K_{m}}{L_{m}}\right)^{\gamma}\left[L_{m} \frac{\gamma-\delta}{1-\delta}+L \frac{1-\gamma}{1-\delta}\right]>A_{m}\left(K_{m}\right)^{\gamma}\left(L_{m}\right)^{1-\gamma} \\
\text { Therefore } \beta(\gamma-\delta) L_{m}+\beta(1-\gamma) L>(1-\delta) L_{m}
\end{gathered}
$$

In equilibrium, $X_{m}^{*}=M_{m}$. Thus

$$
\frac{\sigma \theta Q_{m}^{*}}{1+(\mu-1) \beta}=A_{m}\left(\frac{K_{m}}{L_{m}}\right)^{\gamma}\left[\beta \frac{1-\gamma}{1-\delta} L-\left(1-\beta \frac{\gamma-\delta}{1-\delta}\right) L_{m}\right]
$$

Since $\left(1-\beta \frac{\gamma-\delta}{1-\delta}\right)>0, G\left(L_{m}\right)$, the right hand-side of (21), is decreasing in $L_{m}$.

To determine the free-trade equilibrium terms of trade $p_{m}$, let $\mu=1$ and use (7) reproduced here.

$$
p_{m}=\left(\frac{1-\delta}{1-\gamma}\right)\left(\frac{A_{s}}{A_{m}}\right)\left(\frac{L_{m}}{K_{m}}\right)^{\gamma}\left(\frac{K_{s}}{L-L_{m}}\right)^{\delta}
$$

Under free trade, equation (21) can also be written as

$$
L_{m}\left(\sigma \frac{\gamma-\delta}{1-\gamma}+1\right)+\sigma\left(\frac{1-\delta}{1-\gamma}\right)\left(\frac{\theta Q_{m}^{*}}{A_{m}}\right)\left(\frac{L_{m}}{K_{m}}\right)^{\gamma}=\beta L
$$

This equation determines $L_{m}$. The coefficients of both terms on the lefthand side are positive so that the equation is of the form $a L_{m}=\beta L-b L_{m}^{\gamma}$, where $a$ and $b$ are positive.

So, increases in $\theta$ or in $L^{*}$ (which increase $b$ ) lead to a decrease in $L_{m}$; hence they must also decrease $p_{m}$ and improve the home country's terms of trade. This can be shown to improve the welfare of the home country, $W$. (See Appendix A where we show that a decrease in $p_{m}$ increases $W$ as long as the home country imports good $m$ which, in equilibrium, it must.)

The effect of an increase in $\theta$ on the foreign country's welfare is ambiguous because: 
foreign welfare is

$$
W^{*}=a_{1}^{*} \frac{y^{*}}{p_{m}^{\beta}}=a_{1}^{*} \frac{p_{m} \theta Q_{m}^{*}}{p_{m}^{\beta}}
$$

The positive constant $a_{1}^{*}$ depends on fixed parameters such as $\beta, \gamma, \delta$ and $\sigma$.

As we have just seen, an increase in $\theta$ also lowers $p_{m}$. Therefore the welfare of the foreign country may increase or decrease. This is evidence of the possibility of immiserising growth.

In this section we have characterized the equilibrium under both free trade and trade restrictions. There is always a positive (resp. negative) relationship between the price of the good, $p_{m}$, in the home country and the size of its manufacturing industry (resp. imports). Under free trade the foreign country exports are a fixed proportion of its output, $\theta Q_{m}^{*}$. Increases in $\theta$, the technology of the foreign country, lead to a decrease in the size of the home industry, hence a decrease in its home price and an increase in welfare; this is true, irrespective of trade conditions as long as the home country produces both goods.

\subsection{A Complete Specialization FreeTrade Equilibrium after a Technology Transfer}

In this section we will denote the values of all variables under specialization with a ${ }^{\wedge}$. Suppose now that, as a consequence of a technological transfer from the home country to the foreign country (therefore an increase in $\theta$ ), the world has become specialized with the home country producing good $s$ only, because the foreign country is now equipped with productivity $\theta>$ 1. As we have seen increases in $\theta$ shrink the home manufacturing industry and when its size falls under $\bar{L}_{m}$, it must shut down and employs no one. Hoever $\hat{L}_{s}<L$ and there is unemployment. The reason why some workers previously employed in the manufacturing industry do not have jobs in the sophisticated industry, although the labor market is flexible, is that they lack the required skills. We have assumed that a portion $\bar{L}$ of the total 
manufacturing workforce $L$ cannot work in the sophisticated industry and are unemployed. It follows that $\hat{L}_{s}=L-\bar{L}$.

In this situation $\bar{L}$ agents would have no income and zero consumption. This is not a tenable proposition. There are unemployment benefits and other social welfare payments, plus family transfers, to support people without their own income. For simplicity we assume that transfer payments are such that all individuals in the home country share the same consumption level. Since preferences are homothetic, it is only per capita income, $y$, that determines demand (given the population size).

$$
\begin{gathered}
\hat{y}=\frac{A_{s}\left(K_{s}\right)^{\delta}(L-\bar{L})^{1-\delta}}{L} \\
\hat{c}_{m}=\beta \frac{A_{s}\left(K_{s}\right)^{\delta}(L-\bar{L})^{1-\delta}}{L \hat{p}_{m}}, \hat{c}_{s}=\sigma \frac{A_{s}\left(K_{s}\right)^{\delta}(L-\bar{L})^{1-\delta}}{L}
\end{gathered}
$$

The home country exports

$$
\hat{Q}_{s}-L \hat{c}_{s}=\beta A_{s}\left(K_{s}\right)^{\delta}(L-\bar{L})^{1-\delta}
$$

and imports

$$
L \hat{c}_{m}=\beta \frac{A_{s}\left(K_{s}\right)^{\delta}(L-\bar{L})^{1-\delta}}{\hat{p}_{m}}
$$

The foreign country production, exports and imports are as before. So it exports $\sigma \theta Q_{m}^{*}$ units of good $m$

and imports $p_{m} \sigma \theta Q_{m}^{*}$ units of good $s$.

The balance of trade equation yields

$$
\hat{p}_{m}=\frac{\beta A_{s}\left(K_{s}\right)^{\delta}(L-\bar{L})^{1-\delta}}{\sigma \theta Q_{m}^{*}}
$$

Substituting (26) into (23) we have the new (post-manufacturing industry collapse) equilibrium solutions 


$$
\begin{gathered}
\hat{c}_{m}=\frac{\sigma \theta Q_{m}^{*}}{L}, \hat{c}_{s}=\frac{\sigma A_{s}\left(K_{s}\right)^{\delta}(L-\bar{L})^{1-\delta}}{L} \\
\hat{c}_{m}^{*}=\frac{\beta \theta Q_{m}^{*}}{L^{*}}, \hat{c}_{s}^{*}=\frac{\beta A_{s}\left(K_{s}\right)^{\delta}(L-\bar{L})^{1-\delta}}{L^{*}} \\
\hat{W}=a_{2} \frac{Q_{s}}{\hat{p}_{m}^{\beta}}=a_{2}\left(\theta Q_{m}^{*}\right)^{\beta}\left[A_{s}\left(K_{s}\right)^{\delta}(L-\bar{L})^{1-\delta}\right]^{\sigma} \\
\hat{W}^{*}=a_{2}^{*} \theta Q_{m}^{*} \hat{p}_{m}^{\sigma}=a_{2}^{*}\left(\theta Q_{m}^{*}\right)^{\beta}\left[A_{s}\left(K_{s}\right)^{\delta}(L-\bar{L})^{1-\delta}\right]^{\sigma}
\end{gathered}
$$

where $a_{2}$ and $a_{2}^{*}$ are fixed positive constants.

In this section we have characterized the terms of trade, consumption and welfare after the collapse of the home industry. The effect of a better technology in the foreign country is to increase the consumption of the manufacturing good everywhere, but not that of the sophisticated good. Welfare also increases everywhere. One policy implication is that if, for reasons outside its control, technology flows to the foreign country and forces the end of manufacturing at home, the home country should not fight a rear guard battle but, on the contrary favorize more transfers. The price decreases and every agent's welfare increases. Given $\theta$, the larger the portion of workers $\bar{L}$ who lack some skills, the lower the price, but the lower the welfare in both countries.

\subsection{Import Restrictions to Safeguard the Home Coun- try Manufacturing Sector}

There are clearly welfare costs to the collapse of the manufacturing industry and its ensuing unemployment of resources (some labor and all of manufacturing capital).

For this reason, suppose that the home country restricts imports so that its manufacturing industry does not collapse. That is, it maintains a manufacturing workforce equal to $L_{m} \geqslant \bar{L}_{m}$. 
We investigate the effects of changes in $\theta$ and in the chosen $L_{m}$.

From equation (21) we obtain the equilibrium value of $\mu$, the ratio of home over foreign prices,

$$
1+(\mu-1) \beta=\frac{\sigma \theta A_{m}^{*}\left(K^{*}\right)^{\gamma}\left(L^{*}\right)^{1-\gamma}}{A_{m}\left(\frac{K_{m}}{L_{m}}\right)^{\gamma}\left[\beta \frac{1-\gamma}{1-\delta} L-\left(1-\beta \frac{\gamma-\delta}{1-\delta}\right) L_{m}\right]}
$$

so that, with a fixed $L_{m}, \mu$ is fixed too. An increase in $\theta$ or $L_{m}$ unambiguously increases $\mu$.

From (18) and (30)we have the foreign country's export, $X_{m}^{*}$.

$$
X_{m}^{*}=A_{m}\left(\frac{K_{m}}{L_{m}}\right)^{\gamma}\left[\beta \frac{1-\gamma}{1-\delta} L-\left(1-\beta \frac{\gamma-\delta}{1-\delta}\right) L_{m}\right]
$$

Once again $X_{m}^{*}$ is constant, given $L_{m}$. It decreases with $\bar{L}_{m}$.

Equation (16) can be written as

$$
\left.L^{*} c_{s}^{*}=\sigma\left[p_{m}^{*} \theta Q_{m}^{*}+(\mu-1) p_{m}^{*}\right) X_{m}^{*}\right]
$$

where,

$$
X_{m}^{*}=\frac{\theta Q_{m}^{*}}{1+\mu \beta / \sigma}
$$

The trade balance equation is

$$
L c_{s}+L^{*} c_{s}^{*}=A_{s}\left(K_{s}\right)^{\delta}\left(L-L_{m}\right)^{1-\delta}
$$

where

$$
L c_{s}=\sigma \mu p_{m}^{*} A_{m}\left(\frac{K_{m}}{L_{m}}\right)^{\gamma}\left[\frac{\gamma-\delta}{1-\delta} L_{m}+\frac{1-\gamma}{1-\delta} L\right]
$$

The trade balance equation becomes:

$$
\left(p_{m}-p_{m}^{*}\right) X_{m}^{*}+p_{m} A_{m}\left(\frac{K_{m}}{L_{m}}\right)^{\gamma}\left[\frac{\gamma-\delta}{1-\delta} L_{m}+\frac{1-\gamma}{1-\delta} L\right]=\frac{1}{\sigma} A_{s}\left(K_{s}\right)^{\delta}\left(L-L_{m}\right)^{1-\delta}-\theta p_{m}^{*} Q_{m}^{*}
$$


$p_{m}^{*}\left[(\mu-1) X_{m}^{*}+\mu A_{m}\left(\frac{K_{m}}{L_{m}}\right)^{\gamma}\left[\frac{\gamma-\delta}{1-\delta} L_{m}+\frac{1-\gamma}{1-\delta} L\right]+\theta Q_{m}^{*}\right]=\frac{1}{\sigma} A_{s}\left(K_{s}\right)^{\delta}\left(L-L_{m}\right)^{1-\delta}$

Therefore $p_{m}^{*}$ is uniquely determined once $L_{m}$ and $\theta$ are known.

When $L_{m}$ is fixed, so is $p_{m}$. An increase in $\theta$ in this case (more technology transfer) would increase $\mu$ therefore decrease $p_{m}^{*}$. But the foreign country does not face worse terms of trade because, with $p_{m}$ fixed, a decrease in $p_{m}^{*}$ increases its profit from trade.

We now show that, given $L_{m}$, the foreign country's income, $Y^{*}$, is also constant and independent of $\theta$.

$Y^{*}=p_{m}^{*} \theta Q_{m}^{*}+L^{*} t^{*}=\mu^{-1} p_{m} \theta Q_{m}^{*}+X_{m}^{*}\left(p_{m}-p_{m}^{*}\right)=p_{m} X_{m}^{*}+\mu^{-1} p_{m}\left(\theta Q_{m}^{*}-X_{m}^{*}\right)$

and using (32) and simplifying

$$
Y_{m}^{*}=p_{m} X_{m}^{*} / \sigma
$$

Technology transfers have no effect on the foreign country's nominal income in equilibrium. This result is due to the fact that good $s$ is the numeraire. Real income has increased as we now see. Since $p_{m}^{*}$ decreases with a higher $\theta$ and $c_{s}^{*}=\sigma Y^{*} / L$ while $c_{m}^{*}=\beta Y^{*} / L p_{m}^{*}$, the welfare of the foreign country unambiguously increases.

We now investigate the effect of an increase in $L_{m}$ on $Y^{*}$.

From (31) and (7)

$$
p_{m} X_{m}^{*}=A_{s}\left(\frac{K_{s}}{L-L_{m}}\right)^{\delta}\left[\left[\beta L-\frac{(1-\delta-\beta(\gamma-\delta)) L_{m}}{1-\gamma}\right]\right]
$$

Taking the derivative of the rhs of this equation wrt $L_{m}$ we have,skipping multiplicative constants and after simplification $-(1-\beta \gamma) L+(1-\delta-\beta \gamma+\beta \delta) L_{m}=(1-\beta \gamma)\left[L_{m}-L\right]-\delta(1-\beta) L_{m}<0$ 
An increase in $L_{m}$ decreases the exports of the foreign country and increases $p_{m}$, but their product decreases so that the foreign country is made poorer by a tightening in import restrictions by the home country. We can show that $c_{m}^{*}$ goes up (because $\theta Q_{m}^{*}$ is constant and $X_{m}^{*}$ decreases) but $c_{s}^{*}$ goes down as $Y^{*}$ decreases.

We now look at the effects of an increase in $L_{m}$ on the home country.

$$
\begin{gathered}
c_{s}=\sigma\left(\frac{1-\delta}{1-\gamma}\right)\left(\frac{A_{s}}{A_{m}}\right)\left(\frac{L_{m}}{K_{m}}\right)^{\gamma}\left(\frac{K_{s}}{L-L_{m}}\right)^{\delta} A_{m}\left(\frac{K_{m}}{L_{m}}\right)^{\gamma}\left[L_{m}\left(\frac{\gamma-\delta}{1-\delta}\right)+L\left(\frac{1-\gamma}{(1-\delta)}\right)\right] \frac{1}{L} \\
c_{s} \text { is proportional to }\left(L-L_{m}\right)^{-\delta}\left[(\gamma-\delta) L_{m}+(1-\gamma) L\right]
\end{gathered}
$$

Its derivative has the sign of $\left.\gamma(1-\delta)\left(L-L_{m}\right)+\delta(1-\delta) L_{m}\right)>0$

$$
\frac{d c_{s}}{d L_{m}}>0
$$

Note that $Y$ is proportional to $c_{s}$, so it increases with $L_{m}$ as well.

$$
c_{m}=\beta A_{m}\left(\frac{K_{m}}{L_{m}}\right)^{\gamma}\left[L_{m}\left(\frac{\gamma-\delta}{1-\delta}\right)+L\left(\frac{1-\gamma}{(1-\delta)}\right)\right] \frac{1}{L}
$$

Its derivative has the sign of $\left.\left(L_{m}\right)^{-\gamma-1}(1-\gamma)\left[\gamma\left(L_{m}-L\right)-\delta L_{m}\right)\right]<0$

$$
\frac{d c_{m}}{d L_{m}}<0
$$

If the home country increases $L_{m}$ ( from any level - whether it is the free trade level or a level already fixed by the home country), then its consumption of the sophisticated good goes up and that of the manufactured good decreases, although its home production has increased. This is because $p_{m}$ goes up, making it more expensive. Its income has increased as we noted. This is why $c_{s}$ has increased, although its production has decreased.

In this section we have characterized the outcomes of a policy of trade restrictions imposed by the home country in order to ensure its manufacturing industry remains viable.

These restrictions have been modeled as fixing the level of employment in the manufacturing industry. Once the size of the home manufacturing 
industry has been fixed, its price at home is fixed (but increasing with it ), foreign exports are fixed (but decreasing with it), the foreign price is fixed (but increasing with it), foreign GDP is fixed (but decreasing with it) and foreign welfare is fixed as well (but decreasing with it).

We now summarize the effects of changes in foreign technology, $\theta$, taking the trade restrictions as given - thereby fixing the size of the home manufacturing industry. An increase in foreign technology decreases the foreign country's price and increases its welfare (although it does not alter its nominal income, which is expressed in terms of the sophisticated good). This is because it allows it to make higher profits from foreign trade.

\section{Technology Transfers, Industry Protection and Welfare}

After analysing the various possibilities separately, we know attempt to compare them.

We can calculate the utility of the typical agent in a non-specialized world and in a specialized world. We know that technology transfers are beneficial as long as the manufacturing industry of the home country doesn't collapse. Consider then the marginal situation where $\theta$ is such that the equilibrium value of $L_{m}$ is precisely $\bar{L}_{m}$, the value below which the industry is unsustainable. The manufacturing industry of the home country, under free trade, is on the verge of collapse. The world is on a cusp between nonspecialization and complete specialization. Let us call this value $\bar{\theta}$. The link between $\bar{L}_{m}$, an exogenous value, and $\bar{\theta}$ is given by (21), reproduced here, with the critical values of $\theta$ and $L_{m}$ and $\mu=1$.

$$
\begin{aligned}
& \sigma \bar{\theta} Q_{m}^{*}=\bar{Q}_{m}\left[\left(\beta \frac{\gamma-\delta}{1-\delta}-1\right)+\beta \frac{(1-\gamma) L}{(1-\delta) \bar{L}_{m}}\right] \\
& Y\left(\bar{L}_{m}\right) / p_{m} \equiv \bar{Q}_{m}\left[\left(\frac{\gamma-\delta}{1-\delta}\right)+\frac{L}{\bar{L}_{m}}\left(\frac{1-\gamma}{(1-\delta)}\right)\right]
\end{aligned}
$$


(see (9)) where $\bar{Q}_{m}$ is the amount of manufactured good at $\bar{L}_{m}$. Before the collapse, the $s$ industry employs $L_{s}=L-\bar{L}_{m}$, which differs from its labor force after the collapse, $L-\bar{L}$.

The utility level is, before the collapse, when $\bar{\theta}$ and $\bar{L}_{m}$ have just been reached is

$$
v\left(\bar{L}_{m}\right)=\left[\beta D\left(\bar{L}_{m}\right) \frac{1}{L}\right]^{\beta}\left[\sigma p_{m} D\left(\bar{L}_{m}\right) \frac{1}{L}\right]^{\sigma}
$$

and using the expression for $p_{m}$ in $(7)$ we obtain

$v\left(\bar{L}_{m}\right)=[\beta]^{\beta}[\sigma]^{\sigma} \frac{\bar{Q}_{m}}{L}\left[\frac{\gamma-\delta}{1-\delta}+\frac{L}{\bar{L}_{m}} \frac{1-\gamma}{(1-\delta)}\right]\left[\frac{1-\delta}{1-\gamma} \frac{A_{s}}{A_{m}}\left(\frac{\bar{L}_{m}}{K_{m}}\right)^{\gamma}\left(\frac{K_{s}}{L-\bar{L}_{m}}\right)^{\delta}\right]^{\sigma}$

The pre-collapse utility is independent of $\theta$.

After a transfer of technology above $\bar{\theta}$, the manufacturing industry collapses in the home country, and the utility level is - see Section 3.2

$$
v(\bar{L}, \theta)=\frac{\sigma}{L}\left(\theta Q_{m}^{*}\right)^{\beta}\left[A_{s}\left(K_{s}\right)^{\delta}(L-\bar{L})^{1-\delta}\right]^{\sigma}
$$

The post-collapse utility level is an increasing function of $\theta$.

We now show that, at the switch (when $\theta$ goes through $\bar{\theta}$ ) the utility level of the home country suffers a discrete drop. If this were not the case (specialization is better than non-specialization) then $v(\bar{L}, \theta) \geq v\left(L_{m}\right)$ or, using (35) and after cancelling out terms

$$
\begin{gathered}
{\left[\beta\left(L \frac{1-\gamma}{1-\delta}+\bar{L}_{m} \frac{\gamma-\delta}{1-\delta}\right)-\bar{L}_{m}\right]^{\beta}(L-\bar{L})^{(1-\delta) \sigma}\left(L-\bar{L}_{m}\right)^{\delta \sigma} \geq} \\
\beta^{\beta}\left(\frac{1-\delta}{1-\gamma}\right)^{1-\beta}\left[\bar{L}_{m}\left(\frac{\gamma-\delta}{1-\delta}\right)+L \frac{1-\gamma}{1-\delta}\right]
\end{gathered}
$$

Under the assumption that $\bar{L}<\bar{L}_{m}$, the above condition can never be met (See Appendix C) and the country experiences a discrete drop in welfare 
when its industry collapses. Further increases in $\theta$ may restore or improve welfare in the home country.

We now show that, at the switch (when $\theta$ goes through $\bar{\theta}$ ) the price of good $m$ increases sharply.

Under free trade at $\bar{L}_{m}, p_{m}$ must equal the ratio of marginal utilities for either country, hence consumptions can be replaced with total productions. We obtain

$$
p_{m}=\frac{\beta A_{s}\left(K_{s}\right)^{\delta}\left(L-\bar{L}_{m}\right)^{1-\delta}}{\sigma\left[\bar{\theta} Q_{m}^{*}+A_{m}\left(K_{m}\right)^{\gamma}\left(\bar{L}_{m}\right)^{1-\gamma}\right]}\left(\text { Free Trade at } \bar{L}_{m}\right)
$$

Under specialization, from (26)

$$
p_{m}=\frac{\beta A_{s}\left(K_{s}\right)^{\delta}(L-\bar{L})^{1-\delta}}{\sigma \bar{\theta} Q_{m}^{*}}(\text { Specialization at } \bar{\theta})
$$

In this first expression (the non-specialized case) the numerator is smaller and the denominator is strictly larger. If $\theta$ increases further the price $p_{m}$ under specialization may decrease sufficiently to reverse this ranking. In Figure 1 the non-specialized case is at N, with the slope of the tangent equal to $-p_{m}$ and the specialzed case is at $\mathrm{S}$, with a steeper price line which is determined in part by the technology level of the foreign country. The section of the transformation curve between $\mathrm{N}$ and $\mathrm{S}$ is not available.

The lower bound on $\theta$ is $\tilde{\theta}$.

$\theta \geqslant \frac{\beta}{\sigma} \frac{\bar{Q}_{m}}{Q_{m}^{*}}\left[\frac{1-\delta}{1-\gamma}\right]^{\sigma / \beta}\left[\frac{\gamma-\delta}{1-\delta}+\frac{L}{\bar{L}_{m}} \frac{1-\gamma}{1-\delta}\right]^{1 / \beta}\left[\frac{L}{\bar{L}_{m}}-1\right]^{-\sigma / \beta}\left[\frac{\left(L-\bar{L}_{m}\right)}{L-\bar{L}}\right]^{\sigma(1-\delta) / \beta} \equiv \tilde{\theta}$

This level of technology transfer, $\tilde{\theta}$, insures that the home country is as well or better off after the transfer of technology has induced the collapse of its manufacturing industry. It is clear that a larger foreign country requires a lower technology transfer because efficiency gains are positively related to the size of the country that receives the transfer. Also, if a larger portion of the 
workforce has non-transferable skills (higher $\bar{L}$ ), a larger transfer is required because this parameter reflects the degree of rigidity in the home country workforce, hence the pain of adjustment after the collapse. Large efficiency gains are required to make up for strong rigidity. Finally we note that there are no overall scale effects: from(38) we see that proportional increases in all $L$ and $K$ values have no effect on the critical $\tilde{\theta}$ value, or indeed on utility levels.

Although it is true that the highest possible $\theta$ is best for the home country after its industry has collapsed, $\tilde{\theta}$ establishes a benchmark which must be reached if a higher utility is to be achieved under free trade.

We now investigate the choice by the home country of the trade restriction $L_{m}$.

Home GDP, $Y\left(L_{m}\right)$, is completely determined for any fixed $L_{m}$ value $(\operatorname{see}(9))$

$$
Y\left(L_{m}\right)=\frac{1-\delta}{1-\gamma} A_{s}\left(\frac{K_{s}}{L-L_{m}}\right)^{\delta}\left[\frac{\gamma-\delta}{1-\delta} L_{m}+\frac{1-\gamma}{1-\delta} L\right]
$$

The utility level, under import restrictions $L_{m}$ ( The $s$ industry employs $L_{s}=L-L_{m}$, which differs from its labor force after the collapse, $L-\bar{L}$.) is

$$
\begin{gathered}
v\left(L_{m}\right)=\left[\beta Y\left(L_{m}\right) \frac{1}{L p_{m}}\right]^{\beta}\left[\sigma Y\left(L_{m}\right) \frac{1}{L}\right]^{\sigma} \\
v\left(L_{m}\right)=\frac{Y\left(L_{m}\right)}{L} \beta^{\beta} \sigma^{\sigma}\left[\frac{1-\delta}{1-\gamma} \frac{A_{s}}{A_{m}}\left(\frac{L_{m}}{K_{m}}\right)^{\gamma}\left(\frac{K_{s}}{L-L_{m}}\right)^{\delta}\right]^{-\beta} \\
=\frac{A_{m} \beta^{\beta} \sigma^{\sigma}}{L}\left[\frac{1-\delta}{1-\gamma} \frac{A_{s}}{A_{m}}\right]^{1-\beta}\left(\frac{L_{m}}{K_{m}}\right)^{-\beta \gamma}\left(\frac{K_{s}}{L-L_{m}}\right)^{\delta \sigma}\left[\frac{\gamma-\delta}{1-\delta} L_{m}+\frac{1-\gamma}{1-\delta} L\right]
\end{gathered}
$$

Under trade restrictions at $L_{m}$, home welfare is independent of $\theta$. This expression is decreasing in $L_{m}$ for its relevant range. (See Appendix B for the proof.) The utility of the home country is a decreasing function of its 
artificially imposed manufacturing size. Therefore the best level of industry protection is $\bar{L}_{m}$, the minimum size required to operate.

We now further investigate the desirability of supporting an ailing industry.

Consider the two following situations, both with $\theta>\bar{\theta}$ : Trade restrictions at $\bar{L}_{m}$ versus Specialization.

Note the former is different from free trade at $\bar{L}_{m}$ because, although when $\theta=\bar{\theta}, L_{m}=\bar{L}_{m}$ imposes no restriction, it does when $\theta>\bar{\theta}$. It is obvious that the larger $\theta$ is, the more likely for specialization to be advantageous. Therefore our question is "How small need $\theta$ be so that supporting a failing industry is worthwhile?" After that, it is best to let free trade enforce specialization and all rationale for supporting the manufacturing industry vanishes.

Under specialization at $\theta>\bar{\theta}$, welfare for the home country is, from (28)

$$
W=\sigma\left(\theta Q_{m}^{*}\right)^{\beta}\left[A_{s}\left(K_{s}\right)^{\delta}(L-\bar{L})^{1-\delta}\right]^{\sigma}
$$

Under trade restrictions $\bar{L}_{m}$ at $\theta>\bar{\theta}$, welfare is,

$$
W=\beta^{\beta} \sigma^{\sigma}\left(p_{m}\right)^{\sigma} A_{m}\left(\frac{K_{m}}{\bar{L}_{m}}\right)^{\gamma}\left[\frac{\gamma-\delta}{1-\delta} \bar{L}_{m}+\frac{1-\gamma}{1-\delta} L\right]
$$

So the requirement for $\theta$ to insure that specialization is better than industry protection at $\bar{L}_{m}$, is

$\beta^{\beta} \sigma^{\sigma}\left(p_{m}\right)^{\sigma} A_{m}\left(\frac{K_{m}}{\bar{L}_{m}}\right)^{\gamma}\left[\frac{\gamma-\delta}{1-\delta} \bar{L}_{m}+\frac{1-\gamma}{1-\delta} L\right]<\sigma\left(\theta Q_{m}^{*}\right)^{\beta}\left[A_{s}\left(K_{s}\right)^{\delta}(L-\bar{L})^{1-\delta}\right]^{\sigma}$

We can use the expression for $p_{m}$ from (7) and after simplification, we have the condition on $\theta$ for not supporting the industry.

$\left(\frac{\beta}{\sigma} A_{m}\right)^{\beta}\left(\frac{1-\gamma}{1-\delta}\right)^{\beta}\left(\frac{K_{m}}{\bar{L}_{m}}\right)^{\beta \gamma}\left(\frac{1}{L-\bar{L}_{m}}\right)^{\delta \sigma}\left[\bar{L}_{m} \frac{\gamma-\delta}{1-\gamma}+L\right]>\left(\theta Q_{m}^{*}\right)^{\beta}\left[\left(L-\alpha \bar{L}_{m}\right)^{1-\delta}\right]^{\sigma}$ 
This restriction is identical to (38) therefore if $\theta>\tilde{\theta}$, it is not worthwhile to support the industry.

The restriction on $\theta$ depends on $\bar{L}_{m}$ and $\bar{L}$. It can also be written as

$$
\frac{\beta}{\sigma} \frac{1-\gamma}{1-\delta} \frac{\bar{Q}_{m}}{Q_{m}^{*}}<\theta \bar{L}_{m}\left[(L-\bar{L})^{1-\delta}\left(L-\bar{L}_{m}\right)^{\delta}\right]^{\sigma / \beta}\left[\bar{L}_{m} \frac{\gamma-\delta}{1-\gamma}+L\right]^{-1 / \beta}
$$

Because of the zero homogeneity property in all labor variables,

$$
\begin{gathered}
1+\sigma / \beta-1 / \beta=0, \text { and with } r=\frac{\bar{L}_{m}}{L}, x=\frac{\bar{L}}{L}, r>x, \text { we have } \\
\frac{\beta}{\sigma} \frac{1-\gamma}{1-\delta} \frac{A_{m}\left(K_{m}\right)^{\gamma}(L)^{1-\gamma}}{Q_{m}^{*}}<\theta r^{\gamma}\left[(1-x)^{1-\delta}(1-r)^{\delta}\right]^{\sigma / \beta}\left[r \frac{\gamma-\delta}{1-\gamma}+1\right]^{-1 / \beta}
\end{gathered}
$$

Lemma 1 in Appendix B shows that the expression on the rhs in increasing in $r$. This yields an explicit upper bound on $\bar{L}$ (through $x=\bar{L} / L$ ) to insure it is better to let the industry collapse rather than support it at $\bar{L}_{m}$. If $\bar{L}$ is too big the loss of unused labor from collapse is too great and support isn't warranted.

We can look at the condition another way. Rewrite it as

$$
\begin{gathered}
\frac{\beta}{\sigma} \frac{1-\gamma}{1-\delta} \frac{A_{m}\left(K_{m}\right)^{\gamma}(L)^{1-\gamma}}{\theta A_{m}^{*}\left(K^{*}\right)^{\gamma}\left(L^{*}\right)^{1-\gamma}}\left[r^{-\gamma}(1-r)^{-\delta \sigma / \beta}\left[r \frac{\gamma-\delta}{1-\gamma}+1\right]^{1 / \beta}\right]<(1-x)^{(1-\delta) \sigma / \beta} \\
\text { or } \frac{F\left(\frac{\bar{L}_{m}}{L}\right)}{(\theta)^{\beta /(1-\delta) \sigma}}<\frac{L-\bar{L}}{L} \equiv \frac{\hat{L}_{s}}{L}, \text { where } F^{\prime}<0, \text { by Lemma } 1
\end{gathered}
$$

This shows that if the relative size of the sophisticated industry, after collapse, is large enough, then it is better not to support the manufacturing industry, given $\theta$. This lower bound on $\frac{\hat{L}_{s}}{L}$ is smaller, the larger the relative minimum size of the manufacturing industry, $\frac{\bar{L}_{m}}{L}$; the case against support is re-inforced if the relative size of the supported industry is larger. The effect of 
a larger $\theta$ is qualitatively the same; a more efficient technology in the foreign country makes a stronger case against support.

These results are illustrated in Figure 2. This diagram represents equation (44). For a given minimum size of the manufacturing industry, denoted by $r$ on the horizontal axis, and a level of technology Low $\theta$ intervention is warranted if the size of the post-collapse of the sophisticated industry is below $\boldsymbol{X}$ on the vertical axis ( i. e. if unemployment would be high). If the higher the level of technology High $\theta$ is acquired by the foreign country, intervention is warranted for a lower size of the sophisticated industry, $x$ when only a small portion of workers is unemployable. The higher efficiency of the foreign country mitigates in favor of specialization under free trade. We can use a somewhat similar reasoning (Switching axes so that in this case. Support is to the left and Specialization is to the right in Figure 3.) to explain why, given $\bar{L}$, hence the size of the sophisticated industry after specialization (say at $x$ on the vertical axis), a higher level of technology will allow collapse at a smaller minimum size of manufacturing than if $\theta$ is high ( $r$ instead of $\boldsymbol{R}$, on the horizontal axis). When the foreign country is more efficient, support for home manufacturing less useful.

If we assume that the home country can only transfer the technology that it posesses, the highest value of $\theta$ is $A_{m} / A_{m}^{*}$. Therefore this puts lower bounds on the size of both the minimum size manufacturing industry and the future size of the sophisticated industry that warrant protection. The conclusion is inescapable (see Figure 2): technology transfers adversely affect arguments in favor industry protection at home.

In this section we investigated the relationships between technology $\theta$, unemployable workers $\bar{L}$ after the collapse, the trade restriction $L_{m}$ and how they affect the welfare of the home country faced with the choice between keeping its manufacturing industry and supporting out of work individuals.

First we considered - under free trade - the situation when $\theta$ goes through 
$\bar{\theta}$ and the the manufacturing industry collapses. We showed that the country experiences a discrete drop in welfare and that the the price of good $m$ rises sharply. Further transfers of technology to the foreign country might reverse these results.

Secondly we showed that the utility of the home country is a decreasing function of an artificially imposed manufacturing industry size. Therefore the best level of $L_{m}$ is $\bar{L}_{m}$, the minimum size required to operate. This is true for any level of technology that would otherwise induce the collapse of the manufacturing industry in the home country.

Thirdly we identified a condition that makes supporting a failing industry worthwhile. It can be interpreted in several ways. When $\theta$ is small enough, support is warranted; for a higher technology transfer, it is best to let free trade enforce specialization. Another interpretation is that if the relative size of the sophisticated industry post-collapse is large enough ( or the minimum size of the manufacturing industry small enough) it is best to specialize. The maximum value of $\theta$ puts a lower bound on the size of the manufacturing industry that warrants protection.

Technology transfers adversely affect arguments for industry protection at home.

\section{Conclusion}

Technology transfers occur and whole industries disappear in some countries. Here we analyze the interactions between the various rigidities that may lead to it.

There are two countries, home and foreign, and two goods. The manufactured good and the sophisticated good that only the home country can produce.

Labor is mobile between industries but a portion of workers in the manu- 
facturing industry are not employable in the sophisticated industry. Capital is industry specific.

The size of the manufacturing industry is essential for its viability. We assume that the industry collapses below a given size.

We characterize equilibrium values under both free trade and trade restrictions. Increases in the technology of the foreign country lead to a decrease in the size of the home industry, hence a decrease in its home price and an increase in welfare; this is true, irrespective of trade conditions but it may lead to the end of manufacturing at home.

After the eventual collapse of the home industry, more transfers of technology in the foreign country increase welfare everywhere.

Interactions between technology transfers, the number of un-re-employable workers and trade restrictions have been assessed on the basis of the welfare of the home country faced with the choice between keeping its manufacturing industry and supporting out of work individuals.

When - under free trade - the technology transfer causes the manufacturing industry to collapse in the home country, it experiences a discrete drop in welfare and the price of the manufactured good rises sharply. Further transfers of technology to the foreign country may reverse these results.

The optimal level of protection is the minimum size required to operate. This is true for any level of technology that would otherwise induce the collapse of the manufacturing industry in the home country.

The condition that makes supporting an ailing industry worthwhile can be interpreted in several ways. When technology transfers are small enough, support is warranted; for a higher technology transfer, it is best to let free trade enforce specialization. Another interpretation is that if the size of the sophisticated industry post-collapse is large enough ( or the minimum size of the manufacturing industry small enough) it is best to specialize. The maximum value of the technology transfer puts a lower bound on the size of 
the manufacturing industry that warrants protection.

The conclusion is inescapable: technology transfers adversely affect arguments for industry protection at home.

The rather abrupt assumptions in our model enable us to draw sharp conclusions about technology transfers and industry closures. Further avenues of investigation are the modalities of the transfer, and their costs to either country.

\section{References}

\section{References}

[1] Buckley, Peter J., and Marc C. Casson. 1981. "The Optimal Timing of a Foreign Direct Investment." Economic Journal, 91(361): 75-87.

[2] Coughlin, Cletus C. 1983. "The Relationship Between Foreign Ownership and Technology Transfer." Journal of Comparative Economics, 7(4): 400-414.

[3] Easterly, William. 2001. The Elusive Quest for Growth: Economists' Adventures and Misadventures in the Tropics. Cambridge, MA: MIT Press.

[4] Ethier, Wilfred J., and James R. Markusen. 1996. "Multinational Firm, Technology Diffusion and Trade." Journal of International Economics, 41(1-2): 1-28.

[5] Glass, Amy J., and Kamal Saggi. 1998. "International Technology Transfer and The Technology Gap." Journal of Development Economics, 55(2): 369-398. 
[6] Hoekman, Bernard M., Keith E. Maskus, and Kamal Saggi. 2005. "Transfer of Technology to Developing Countries: Unilateral and Multilateral Policy Options." World Development, 33(10): 1587-1602.

[7] Horstmann, Ignatus J., and James R. Markusen. 1987. "Strategic Investment and Development of Multinationals." International Economic Review, 28(1): 109-121.

[8] Horstmann, Ignatus J., and James R. Markusen. 1996. "Exploring New Markets: Direct Investment, Contractual Relations and the Multinational Enterprise." International Economic Review, 37(1): 119.

[9] Kabiraj, Tarun, and Sugata Marjit. 2003. "Protecting Consumers through Protection: The Role of Tariff-induced Technology Transfer." European Economic Review 47(1): 113-124.

[10] Lin, Ping, and Kamal Saggi. 1999. "Incentive for Foreign Investment under Imitation." Canadian Journal of Economics 32(5): 1275-1298.

[11] Mansfield, Edwin. 1994. "Intellectual Property Protection, Foreign Investment, and Technology Transfer." International Finance Corporation Discussion Paper 19.

[12] Markusen, James R. 2001. "Contracts, intellectual property rights, and multinational investment in developing countries." Journal of International Economics 53: 189-204.

[13] Mukherjee, Arijit, and Enrico Pennings. 2006. "Tariffs, Licensing and Market Structure." European Economic Review 50(7): 1699-1707.

[14] Niosi, Jorge, Petr Hanel, and Liette Fiset. 1995. "Technology Transfer to Developing Countries through Engineering Firms: The Canadian Experience." World Development 23(10): 1815-1824. 
[15] Rob, Rafael, and Nikolaos Vettas. 2003. "Foreign Direct Investment and Exports with Growing Demand." Review of Economic Studies 70(3): 629-648.

[16] Roy Chowdhury, Indrani, and Prabal Roy Chowdhury. 2001. "A Theory of Joint Venture Life-cycles." International Journal of Industrial Organization 19(3-4): 319-343.

[17] Teece, David J. 1977. "Technology Transfer by Multinational Firms: The Resource Cost of Transferring Technological Know-how." Economic Journal 87(346): 242-61.

Appendix A

$$
W=\max _{c_{s}} U\left(c_{s}, \frac{y\left(p_{m}\right)-c_{s}}{p_{m}}\right)
$$

where

$$
\frac{y\left(p_{m}\right)-c_{s}}{p_{m}}=c_{m}
$$

and

$$
y\left(p_{m}\right)=\frac{1}{L} \max _{L_{m}}\left[p_{m} A_{m}\left(K_{m}\right)^{\gamma}\left(L_{m}\right)^{1-\gamma}+A_{s}\left(K_{s}\right)^{\delta}\left(L-L_{m}\right)^{1-\delta}\right]
$$

We now show that any increase in $p_{m}$ will reduce $W$ as long as $p_{m}$ is consistent with the home country being an importer of good $m$. Using the envelope theorem,

where

$$
\frac{d W}{d p_{m}}=\frac{\partial U}{\partial c_{m}} \frac{\partial c_{m}}{\partial p_{m}}
$$

$$
\begin{aligned}
\frac{\partial c_{m}}{\partial p_{m}} & =\frac{p_{m}\left(\frac{\partial y}{\partial p_{m}}\right)-\left(y\left(p_{m}\right)-c_{s}\right)}{\left(p_{m}\right)^{2}} \\
& =\left(\frac{1}{p_{m}}\right)^{2}\left[p_{m}\left(\frac{A_{m}\left(K_{m}\right)^{\gamma}\left(L_{m}\right)^{1-\gamma}}{L}\right)-p_{m} c_{m}\right] \\
& =\frac{1}{p_{m}}\left[\frac{Q_{m}}{L}-c_{m}\right]
\end{aligned}
$$


Therefore a decrease in $p_{m}$ will increase $W$ as long as the home country imports good $m$.

Appendix B

LEMMA 1: $v(x L)$ is decreasing in $x$ for $x \leq x_{1} \equiv \frac{\beta-\beta \gamma}{(1-\delta)+\beta \delta-\beta \gamma} . x L=L_{m}$.

\section{PROOF}

let

$$
\begin{aligned}
g(x) & \equiv x^{-\beta \gamma}(1-x)^{-\delta \sigma}\left[x\left(\frac{\gamma-\delta}{1-\delta}\right)+\left(\frac{1-\gamma}{1-\delta}\right)\right] \\
& =(1-x)^{-\delta \sigma}\left[\left(\frac{\gamma-\delta}{1-\delta}\right) x^{1-\beta \gamma}+\left(\frac{1-\gamma}{1-\delta}\right) x^{-\beta \gamma}\right]
\end{aligned}
$$

then

$$
\begin{aligned}
g^{\prime}(x)= & (1-x)^{-\delta \sigma}\left[(1-\beta \gamma)\left(\frac{\gamma-\delta}{1-\delta}\right) x^{-\beta \gamma}-\beta \gamma\left(\frac{1-\gamma}{1-\delta}\right) x^{-\beta \gamma-1}\right]+ \\
& \delta \sigma(1-x)^{-\delta \sigma-1}\left[\left(\frac{\gamma-\delta}{1-\delta}\right) x^{1-\beta \gamma}+\left(\frac{1-\gamma}{1-\delta}\right) x^{-\beta \gamma}\right] \\
g^{\prime}(x)= & (1-x)^{-\delta \sigma-1} x^{-\beta \gamma-1}\left[(1-\beta \gamma)\left(\frac{\gamma-\delta}{1-\delta}\right) x-\beta \gamma\left(\frac{1-\gamma}{1-\delta}\right) x\right](1-x) \\
+ & (1-x)^{-\delta \sigma-1} x^{-\beta \gamma-1}\left[\delta \sigma\left(\frac{\gamma-\delta}{1-\delta}\right) x^{2}+\delta \sigma\left(\frac{1-\gamma}{1-\delta}\right) x\right]
\end{aligned}
$$

So the sign of $g^{\prime}(x)$ is the sign of the term

$$
\left[(1-\beta \gamma)\left(\frac{\gamma-\delta}{1-\delta}\right) x-\beta \gamma\left(\frac{1-\gamma}{1-\delta}\right) x\right](1-x)+\left[\delta \sigma\left(\frac{\gamma-\delta}{1-\delta}\right) x^{2}+\delta \sigma\left(\frac{1-\gamma}{1-\delta}\right) x\right]
$$

Which has the same sign as

$$
(\delta-\gamma)[(1-\delta)+(\delta-\gamma) \beta] x^{2}+[\delta(1-\gamma)+(\gamma-\delta)(1+\beta-2 \beta \gamma] x-\beta \gamma(1-\gamma) \equiv f(x)
$$

Note that $f(0)=-\beta \gamma(1-\gamma)<0$ 
We will now show that $f(x)<0$ iff $x<x_{1}$, where, recall eq (??),

$$
x_{1} \equiv \frac{\beta-\beta \gamma}{[(1-\delta)+\beta \delta]-\beta \gamma} \in(0,1)
$$

Consider three cases:

Case 1: $\delta=\gamma$

In this case, $f(x)$ is linear in $x, x_{1}$ is reduced to $\beta$, and $f\left(x_{1}\right)=0$. Since $f(x)<0$ and $f^{\prime}(x)>0$ in this case, it follows that $f(x)<0$ iff $x<x_{1}$.

Case 2: $\delta>\gamma$. Then $f(x)$ has the same sign as

$$
x^{2}+\frac{[\delta(1-\gamma)+(\gamma-\delta)(1+\beta-2 \beta \gamma]}{(\delta-\gamma)[(1-\delta)+(\delta-\gamma) \beta]} x-\frac{\beta \gamma(1-\gamma)}{(\delta-\gamma)[(1-\delta)+(\delta-\gamma) \beta]}
$$

which can be factorized as

$$
\left(x-x_{1}\right)\left(x-x_{2}\right)
$$

where $x_{1}$ is defined above, and

$$
x_{2} \equiv-\frac{\gamma}{\delta-\gamma}<0 \text { since } \delta>\gamma
$$

Then $x-x_{2}>0$ for all $x \in[0,1]$. It follows that $f(x)<0$ for all $x \in\left(0, x_{1}\right)$ and $f(x)>0$ for all $x \in\left(x_{1}, 1\right)$.

Case 3: $\delta<\gamma$. Then the sign of $f(x)$ is opposite to the sign of

$$
\left(x-x_{1}\right)\left(x-x_{2}\right)
$$

where $x_{2} \equiv-\frac{\gamma}{(\delta-\gamma)}>1$ since $\delta<\gamma$. Thus it follows that $f(x)<0$ for all $x \in\left(0, x_{1}\right)$ and $f(x)>0$ for all $x \in\left(x_{1}, 1\right)$.

This completes the proof of lemma 1

\section{Appendix C}

For specialization to be better than non-specialization under free trade the following condition should hold

$$
\left[\beta\left(\frac{1-\gamma}{1-\delta} L+\frac{\gamma-\delta}{1-\delta} \bar{L}_{m}\right)-\bar{L}_{m}\right]^{\beta}(L-\bar{L})^{(1-\delta) \sigma}\left(L-\bar{L}_{m}\right)^{\delta \sigma} \geq
$$




$$
\beta^{\beta}\left(\frac{1-\delta}{1-\gamma}\right)^{1-\beta}\left[\frac{1-\gamma}{1-\delta} L+\frac{\gamma-\delta}{1-\delta} \bar{L}_{m}\right]
$$

The above condition cannot be met as we now show and the country experiences a discrete drop in welfare when its industry collapse.

The lhs is smaller than

$$
\beta^{\beta}\left(\frac{1-\gamma}{1-\delta}\right)^{\beta}\left(L-\bar{L}_{m}\right)^{\beta+\delta \sigma}(L-\bar{L})^{(1-\delta) \sigma}
$$

which is smaller than

$$
\beta^{\beta}\left(\frac{1-\gamma}{1-\delta}\right)^{\beta}\left(L-\bar{L}_{m}\right), \text { since } \bar{L}<\bar{L}_{m} \text { and } \sigma(1-\delta)+\beta+\delta \sigma=1
$$

The rhs is equal to

$$
\beta^{\beta}\left(\frac{1-\delta}{1-\gamma}\right)^{-\beta}\left[\frac{\gamma-\delta}{1-\gamma} \bar{L}_{m}+L\right]
$$

But

$$
L-\bar{L}_{m}<\frac{\gamma-\delta}{1-\gamma} \bar{L}_{m}+L \text { or }-1<\frac{\gamma-\delta}{1-\gamma} \text { or } \gamma-1<\gamma-\delta, \text { since } 0<\delta<1
$$

Therefore the above condition cannot be met and the country experiences a discrete drop in welfare when its industry collapses. 